\title{
A METRICAL STUDY OF MANDIBLE IN EASTERN INDIAN POPULATION
}

\author{
Anjana Dhur1, Bulbul Mukhopadhyay² \\ ${ }_{1}^{1}$ Assistant Professor, Department of Anatomy, Murshidabad Medical College and Hospital, Berhampore, West Bengal, India. \\ ${ }^{2}$ Associate Professor, Department of Physiology, Murshidabad Medical College and Hospital, Berhampore, West Bengal, India.
}

\section{BACKGROUND} ABSTRACT

The mandible forms the lower jaw. It is well-known that skeleton is an excellent material in living and non-living population for genetic, odontological, anthropological and forensic investigations. Next to the pelvis, the skull is the most easily sexed portion of the skeleton. Entire skull may not be readily available and in such cases the mandible plays a vital role in the prediction of sex in an individual. Moreover, the influence of food and ethnicity on individual mandible is also worth mentioning.

\section{MATERIALS AND METHODS}

The present descriptive observational study was conducted using dried cadaveric human mandibles obtained from the Department of Anatomy, RG Kar Medical College, Kolkata and Calcutta Medical College, Kolkata; and Department of Anthropology, University College of Science, Technology and Agriculture, University of Calcutta. Intercanine distance (ICD) and the distance between the two mental foramina (DMF) were measured.

\section{RESULTS}

All metric variables confirmed higher values in male mandibles. Moreover, a correlation coefficient was found out between the two and a linear regression was calculated between the two variables.

\section{CONCLUSION}

It will help us to gain information on mandibular dimorphism and various adaptive features that are influenced by ethnicity. This will further aid in maxillofacial operations and plastic reconstructive surgeries.

\section{KEY WORDS}

Mandible, Skeleton, Skull, Ethnicity.

HOW TO CITE THIS ARTICLE: Dhur A, Mukhopadhyay B. A metrical study of mandible in Eastern Indian population. J. Evolution Med. Dent. Sci. 2018;7(39):4304-4306, DOI: 10.14260/jemds/2018/959

\section{BACKGROUND}

Human skeleton often remains the lone reminder of its past, thereby necessitating the determination of sex (Sexing) in Forensic Sciences and Anthropology.[1] It is often difficult to ascertain the cause of death once the soft tissue is decomposed. The forensic anthropological investigation then plays an important role in probing into the nature and cause of death.

Skeleton is an excellent material for genetic, anthropological, odontological and forensic investigations, both in the living and non-living population. The methods of identification vary and depend upon the availability of bones and their condition. However, the statistical study of anthropometric measurements require a number of subjects or specimens, far in excess of those considered sufficient by earlier anthropologists. The newer methods also demand greater precision in measurements and better control and standardisation of the techniques used in collecting the data. DNA technique is the only method that can give a totally accurate result, but in many cases for several reasons it cannot be applied. Anthropological measurements of the

'Financial or Other Competing Interest': None.

Submission 13-08-2018, Peer Review 08-09-2018,

Acceptance 14-09-2018, Published 24-09-2018.

Corresponding Author:

Dr. Anjana Dhur,

\#93, Narayan Roy Road,

Brajodham Apartment, Flat No. 4A,

Kolkata-700008, West Bengal, India.

E-mail:doc0mini55@gmail.com

DOI: $10.14260 /$ jemds/2018/959 skeleton and comparison with the existing standard data must then be applied when the skeleton is in hand.

Determination of sex has important implications for the study of human evolution too. Size and shape changes may reflect the changes in hominid adaptation through time.[2] Frayer in his study analyses the changes in sexual dimorphism of the dentition, crania and stature of the European population from Upper Paleolithic to present.[3] In some of the earlier studies of dimorphism in non-human primates, it is suggested that the males tend to have a larger body size than the females due to its protection of the group and resources.[4],[5]

In the field of Forensic Osteology, sex determination from skeletal remains, especially from isolated bones has been an age old problem. Differentiation is usually based on the male features that are typically more prominent than the female features. The greater the degree of dimorphism, the more accurate will be the assignment of sex from the skeletal remains. Hormone related changes are the means, whereby sexual differences manifest in many tissues including bone. Thus, the circulating hormones in the body also dictate the basis of sexual dimorphism.

Demographic changes and secular trends also influences the sexual dimorphism of the cranium.[6] These findings are supplemented by the studies of the North American population as well as the Central European population. [7] Diet related factors associated with subsistence economics also influences craniofacial morphology. ${ }^{[8],[9]}$ Moreover, gender, race and habits also influence sexual dimorphism.[10]

Physical anthropologists are much concerned and continually looking for new ways to determine sex from 
human remains. Determination of sex is done either metrically or descriptively (Morphologically). The role of mandible in sex determination is still poorly defined. However, some linear measurements of mandibular dimensions can still be applied when the jaws are at hand.

The mandible (From Latin mandibula, 'jaw bone') or inferior maxillary bone forms the lower jaw. It is the largest, strongest and lowest bone of the face and serves for the reception of lower teeth.[11] It is well-known that the skeleton is an excellent material in the living and non-living population for genetic, anthropological, odontological and forensic investigation. Now, mandible being a part of the skull, the various statistical studies are carried out to obtain the anthropometric data with the principal objective of identification of a person and sex determination when the remains of the body are only available. Moreover, the influence of food and ethnicity on individual mandible is also worth mentioning.

\section{MATERIALS AND METHODS}

The present descriptive observational study was conducted within a period of May 2009 to April 2010, using dry adult human mandibles, where all the study parameters were present prominently with no observable abnormalities and not of the extremes of age. All the observations were recorded by a single person. The study was undertaken at the Department of Anatomy in RG Kar Medical College, Kolkata and Calcutta Medical College and also the Department of Anthropology, University College of Science, Technology and Agriculture, University of Calcutta. The permission of the departments were taken prior to the study. Dried cadaveric human mandibles were selected from the museum of the study area. Proper precautions were taken, so as not to cause any damage to the cadaveric mandible specimens. All measurements were taken in adult mandibles and only during daytime.

The study sample included 102 (one hundred and two) cadaveric human mandibles, out of which 56 (fifty-six) were male and 46 (forty-six) female mandibles. It was a crosssectional, observational study. The intercanine distance (ICD) and the distance between the two mental foramina (DMF) were measured using Martin's sliding callipers and bone marking pen. The dried cadaveric adult mandibles were collected from the places mentioned above and marked numerically. Then, the mid-points of the bases of canines were marked and the distance between the two points measured to find out the Intercanine distance. The distance between the two mental foramina (DMF) was also calculated using slide callipers.

\section{Statistical Analysis}

The results were calculated using SPSS version sixteen statistical software. Student's t-test was then performed, and ' $p$ ' value was found out. Correlations between the groups were done using Pearson's correlation formula. A ' $p$ ' value less than 0.001 was considered significant.

\section{RESULTS}

The following metric values of dried cadaveric human mandibles were compared between male and female and student's t-test performed, and the ' $p$ ' value was found out. A value of $p$ less than 0.001 was considered significant.

\begin{tabular}{|c|c|c|c|c|c|}
\hline & \multicolumn{4}{|c|}{ Sex } & \multirow{2}{*}{} \\
\cline { 2 - 5 } & \multicolumn{2}{|c|}{ Male (56) } & \multicolumn{2}{c|}{ Female (46) } & \\
\hline Variables & Range & $\begin{array}{c}\text { Mean } \pm \\
\text { S.D. }\end{array}$ & Range & $\begin{array}{c}\text { Mean } \\
\pm \text { S.D. }\end{array}$ & $\begin{array}{c}\text { P } \\
\text { value }\end{array}$ \\
\hline (Unit) & & & $2.20 \pm$ & $2.39 \pm$ & $<$ \\
ICD & 2.30 to & $2.68 \pm$ & 2.20 & 0.12 & 0.001 \\
\hline (centimetres) & 3.00 & 0.16 & 2.70 & $0.26 \pm$ & $<$ \\
\hline DMF & 4.30 to & $4.65 \pm$ & 3.90 to & $4.26 \pm$ & 0.001 \\
(centimetres) & 4.90 & 0.16 & 4.70 & 0.19 & 0.001 \\
\hline
\end{tabular}

Table 1. Comparison of ICD and DMF in Male and Female Mandibles

As depicted in Table Number 1, the present study has compared the results of ICD and DMF of cadaveric male and female mandibles and their statistical significance calculated using the student's t-test. All the metric variables confirmed higher values in male mandibles.

Also, the correlation coefficient was found out between intercanine distance and the distance between the two mental foramina that clearly shows a positive correlation in males (0.223) and negative correlation in females $(-0.033)$.

\begin{tabular}{|c|c|c|}
\hline Correlation Coefficients & ICD/DMF & P value \\
\hline Male & 0.223 & $<0.001$ \\
\hline Female & -0.033 & $<0.03$ \\
\hline \multicolumn{2}{|c|}{ Table 2. Correlation Coefficients } \\
\hline
\end{tabular}

Linear regression was also calculated with the ICD as the dependent variable and DMF as the independent variable. Rsquared was 0.343 , which means about $34 \%$ variation in ICD can be explained by its linear regression on DMF.

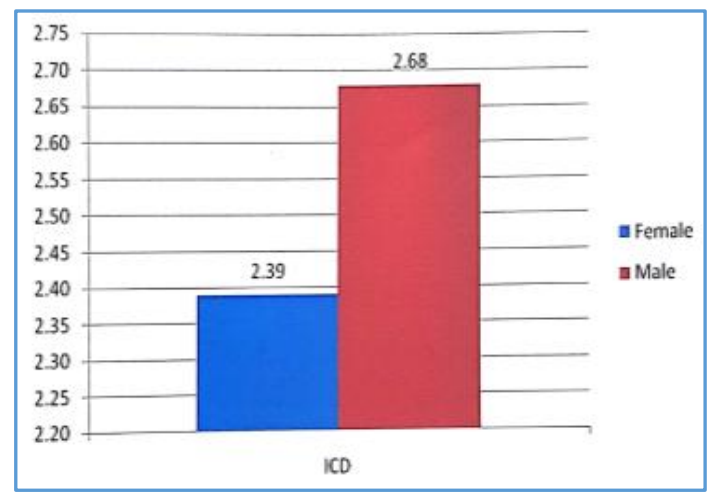

Figure 1. Mean of Intercanine Distance compared between Sexes

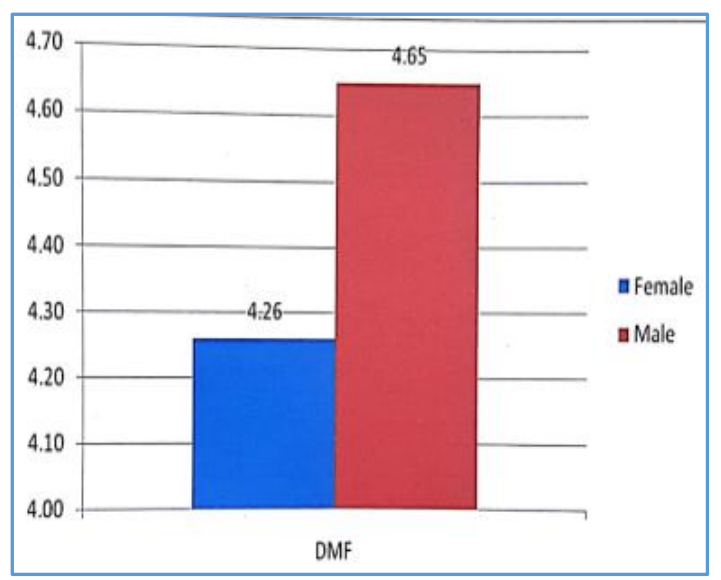

Figure 2. Mean of Distance between the Two Mental Foramina

Compared between sexes. 


\section{DISCUSSION}

The mandible or inferior maxillary bone forms the lower jaw owing largely to the recent works presented in the Biometrika, the mandible is now the part of the skeleton after the cranium which has been described metrically.[12] Mandible, being a component of the skull, the various statistical studies are carried out to obtain the anthropometric date with the principal objective of identification of a person and sex determination when the remains of the body are only available. In our present study, the results of metric measurements of ICD and DMF of cadaveric male and female mandibles were found out and their statistical significance was calculated using student's ttest. All metric variables confirmed higher values in male mandibles, which may be due to strong stature and built.

The mean value of ICD as found out in Eastern Indian Population in this study was $2.68 \mathrm{~cm}$ in males and $2.39 \mathrm{~cm}$ in females (as noted in Table Number 1 and Figure Number 1); whereas, a study conducted in Haryana gave a value of 2.58 $\mathrm{cm}$ and $2.48 \mathrm{~cm}$ respectively.[13] This difference can be attributed to the difference in study population chosen, the former being from Eastern India and the latter from Haryana.

Figure 2 and Table 1 also shows that the distances between mental foramina are statistically significant too. Thus, all the variables being statistically significant between the sexes clearly reflects the existence of definite sexual dimorphism between the sexes and that it is also influenced by food habits and ethnicity.

Correlation coefficient was also found out between ICD and DMF that shows a positive correlation in males $(0.233)$ and a negative correlation in females (-0.033). Therefore, an increase in DMF will cause a simultaneous increase in ICD in males; whereas, in females an increase in DMF will produce a decrease in ICD.

Linear regression was also found out with the ICD as the dependent variable and the DMF as the independent variable. R-squared was 0.0343 , which means about $34 \%$ variation in ICD can be explained by its linear regression on DMF. The regression equation is $\mathrm{ICD}=0.54+0.45 \mathrm{x} \mathrm{DMF}$, i.e. for one unit change in DMF, ICD will change by 0.45 units. The pvalue for the test of significance of the coefficient for DMF is highly significant $(<0.001)$.

\section{CONCLUSION}

Thus, the present study evaluates and compares the influence of sex, race, food and ethnicity on ICD and DMF. It will help us to gain information on mandibular dimensions and various adaptive features that are influenced by ethnicity. This will further aid in maxillofacial operations and plastic reconstructive surgeries.

\section{REFERENCES}

[1] Brinkmann B. Forensic anthropology. International Journal of Legal Medicine 2007;121(6):431-2.

[2] Armelagos GJ, Van Gerven DP. Sexual dimorphism and human evolution: an overview. Journal of Human Evolution 1980;9(5):437-46.

[3] Frayer DW, Wolpoff MH. Sexual dimorphism. Annual Review in Anthropology 1985;14:429-73.

[4] Brace CL. Sexual dimorphism in human evolution. Yearbook of Physical Anthropology 1973;16:31-49.

[5] Trivers RL. Parental investment and sexual selection. Campbell B, edr. Sexual selection and the descent of man, 1871-1971. Chicago, IL: Aldine 1972: p. 136-79.

[6] Buretic-Tomlijanovic A, Ostojic S, Kapovic M. Secular change of craniofacial measures in Croatian younger adults. American J Human Biol 2006;18(5):668-75.

[7] Jantz RL. Cranial changes in Americans: 1850-1975. J Forensic Sci 2001;46(4):784-7.

[8] Perez SI, Bernal V, Gonzalez PN. Morphological differentiation of aboriginal human populations from Tierra del Fuego (Patagonia). Implications for South American peopling. American Journal of Physical Anthropology 2007;133(4):1067-79.

[9] Sardi ML, Novellino PS, Pucciarelli HM. Craniofacial morphology in the Argentine Centre-West: consequences of the transition to food production. American Journal of Physical Anthropology 2006;130(3):333-43.

[10] Gabriel AC. Some anatomical features of the mandible. Journal of Anatomy 1958;92(4):580-6.

[11] Standring S. Head and Neck. Chapter 27. In: Standring S, editor-in-chief. Gray's Anatomy: the anatomical basis of clinical practice. 40 $0^{\text {th }}$ International edn. Philadelphia, USA: Elsevier/ Churchill Livingstone 2008: p. 530.

[12] Cleaver FH. A contribution to the Biometric Study of the Human Mandible. Biometrika 1937;29(1-2):80112.

[13] Rai B, Anand S, Madan M, et al. Criteria for determination of sex from mandible. The Internet Journal of Dental Science 2006;4(2)1-5. 